\title{
Design of a Percussion and Electric Primer Gun Firing Power Supply
}

\author{
by Peter T. Bartkowski
}




\section{NOTICES}

\section{Disclaimers}

The findings in this report are not to be construed as an official Department of the Army position unless so designated by other authorized documents.

Citation of manufacturer's or trade names does not constitute an official endorsement or approval of the use thereof.

Destroy this report when it is no longer needed. Do not return it to the originator. 


\title{
Army Research Laboratory
}

Aberdeen Proving Ground, MD 21005-5069

ARL-TR-6987

July 2014

\section{Design of a Percussion and Electric Primer Gun Firing Power Supply}

\author{
Peter T. Bartkowski \\ Weapons and Materials Research Directorate, ARL
}




\section{REPORT DOCUMENTATION PAGE}

Form Approved OMB No. 0704-0188

Public reporting burden for this collection of information is estimated to average 1 hour per response, including the time for reviewing instructions, searching existing data sources, gathering and maintaining the data needed, and completing and reviewing the collection information. Send comments regarding this burden estimate or any other aspect of this collection of information, including suggestions for reducing the burden, to Department of Defense, Washington Headquarters Services, Directorate for Information Operations and Reports (0704-0188), 1215 Jefferson Davis Highway, Suite 1204, Arlington, VA 22202-4302. Respondents should be aware that notwithstanding any other provision of law, no person shall be subject to any penalty for failing to comply with a collection of information if it does not display a currently valid OMB control number.

PLEASE DO NOT RETURN YOUR FORM TO THE ABOVE ADDRESS.

\begin{tabular}{|l|l|}
\hline $\begin{array}{l}\text { 1. REPORT DATE }(D D-M M-Y Y Y Y) \\
\text { July } 2014\end{array}$ & $\begin{array}{l}\text { 2. REPORT TYPE } \\
\text { Final }\end{array}$ \\
\hline
\end{tabular}

4. TITLE AND SUBTITLE

3. DATES COVERED (From - To)

December 2013

Design of a Percussion and Electric Primer Gun Firing Power Supply

5a. CONTRACT NUMBER

\begin{tabular}{|c|c|}
\hline & 5b. GRANT NUMBER \\
\hline & 5c. PROGRAM ELEMENT NUMBER \\
\hline \multirow{4}{*}{$\begin{array}{l}\text { 6. AUTHOR(S) } \\
\text { Peter T. Bartkowski }\end{array}$} & 5d. PROJECT NUMBER \\
\hline & \\
\hline & 5e. TASK NUMBER \\
\hline & 5f. WORK UNIT NUMBER \\
\hline $\begin{array}{l}\text { 7. PERFORMING ORGANIZATION NAME(S) AND ADDRESS(ES) } \\
\text { U.S. Army Research Laboratory } \\
\text { ATTN: RDRL-WMP-E } \\
\text { Aberdeen Proving Ground, MD } 21005-5069\end{array}$ & $\begin{array}{l}\text { 8. PERFORMING ORGANIZATION } \\
\text { REPORT NUMBER } \\
\text { ARL-TR-6987 }\end{array}$ \\
\hline \multirow[t]{2}{*}{ 9. SPONSORING/MONITORING AGENCY NAME(S) AND ADDRESS(ES) } & 10. SPONSOR/MONITOR'S ACRONYM(S) \\
\hline & $\begin{array}{l}\text { 11. SPONSOR/MONITOR'S REPORT } \\
\text { NUMBER(S) }\end{array}$ \\
\hline
\end{tabular}

\section{DISTRIBUTION/AVAILABILITY STATEMENT}

Approved for public release; distribution is unlimited.

\section{SUPPLEMENTARY NOTES}

\section{ABSTRACT}

The U.S. Army Research Laboratory has designed and built a new power supply to fire laboratory guns in support of armor research. The new power supply is specifically designed to drive a solenoid into a percussion primer or ignite the M52A3B1 electric primer. To reduce power requirements, it uses charged capacitor banks to drive the solenoid or ignite the primer. This report details the design and construction of the power supplies.

\section{SUBJECT TERMS}

power supply, gun, percussion, electric primer, capacitor

\begin{tabular}{|l|l|l|l|l|l|}
\hline \multicolumn{2}{|l|}{ 16. SECURITY CLASSIFICATION OF: } & $\begin{array}{l}\text { 17. LIMITATION } \\
\text { OF ABSTRACT }\end{array}$ & $\begin{array}{l}\text { 18. NUMBER } \\
\text { OF PAGES }\end{array}$ & $\begin{array}{l}\text { 19a. NAME OF RESPONSIBLE PERSON } \\
\text { Peter T. Bartkowski }\end{array}$ \\
\cline { 1 - 1 } $\begin{array}{l}\text { a. REPORT } \\
\text { Unclassified }\end{array}$ & $\begin{array}{l}\text { b. ABSTRACT } \\
\text { Unclassified }\end{array}$ & $\begin{array}{l}\text { c. THIS PAGE } \\
\text { Unclassified }\end{array}$ & UU & 30 & $\begin{array}{l}\text { 19b. TELEPHONE NUMBER (Include area code) } \\
410-278-0210\end{array}$ \\
\hline
\end{tabular}




\section{Contents}

List of Figures $\quad$ iv

$\begin{array}{lr}\text { 1. Introduction } & 1\end{array}$

2. The Existing System $\quad 1$

3. New System Design 1

4. Circuit Design $\quad 2$

$\begin{array}{ll}\text { 5. Unit Construction } & 3\end{array}$

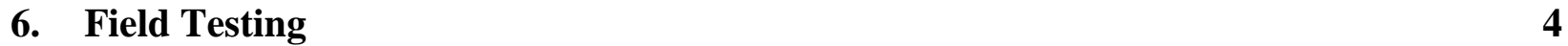

$\begin{array}{lll}\text { 7. Conclusions } & 6\end{array}$

$\begin{array}{ll}\text { Appendix A. Circuit Schematic } & 7\end{array}$

$\begin{array}{ll}\text { Appendix B. Circuit Board Layout } & 9\end{array}$

$\begin{array}{ll}\text { Appendix C. Component List } & 11\end{array}$

$\begin{array}{ll}\text { Appendix D. Instrument Panels } & 15\end{array}$

$\begin{array}{lr}\text { Appendix E. Instrument Case Interior } & 19\end{array}$

$\begin{array}{ll}\text { Appendix F. Photo of Completed Unit } & 21\end{array}$

$\begin{array}{ll}\text { Distribution List } & 23\end{array}$ 


\section{List of Figures}

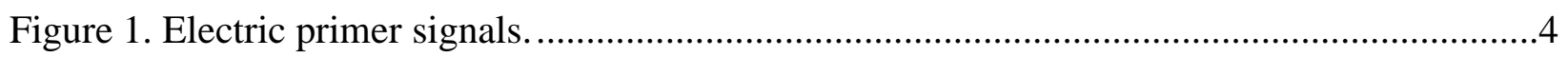

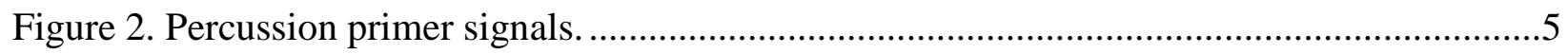

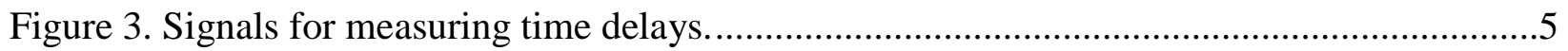




\section{Introduction}

The U.S. Army Research Laboratory has multiple laboratory gun firing ranges that use both percussion and electric primers for initiation. Currently, a combination of a linear power supply and a switch button panel is used to fire the guns. After replacement power supplies failed to adequately perform, an analysis was conducted to determine the power supply requirements. It was found that the design of a dedicated firing unit was the most appropriate way to replace the old hardware, as commercial laboratory gun firing products do not exist.

\section{The Existing System}

The existing firing system consisted of a Hewlett Packard no. 895A linear power supply (0-320 volts of direct current [VDC], 0-1.5 amperes [A]) connected to the firing line via a mechanical switch or solid-state relay to fire the gun. The voltage was varied on the power supply depending on whether a percussion or electric primer was used.

New replacement switching power supplies failed to adequately activate the solenoid used to initiate the percussion primer. The new power supplies could not provide enough surge current for the initial pull of the solenoid, which can be over $50 \mathrm{~A}$. The old linear power supply has large filter capacitors on its output, which does provide the surge current to fire the solenoid. Modern switching power supplies have a much lower capacitance output and are electronically current limiting. Buying a new switching power supply with the necessary current capability would require a unit over $3500 \mathrm{~W}$ and necessitate upgrading the electrical power to support the device.

It was decided that a custom-designed dedicated capacitor-based power supply was a better approach.

\section{New System Design}

The new power supply is designed to fire both the M52A3B1 electric primer and percussion primers. The percussion primer is initiated using a Trombetta solenoid model Q610-A1V24. The M52A3B1electric primer is designed to function with a 2- $\mu \mathrm{F}$ capacitor charged to $160 \mathrm{VDC}$. Due to the long length of some of the firing lines in use and the large surge currents, a $60-\mu \mathrm{F}$ capacitor charged to 190 VDC was chosen. The Trombetta solenoid has a specified operating voltage of 24 VDC. Solenoids can typically be over driven to a certain extent if they are used in a 
pulsed mode of operation that has no continuous draw. Tests were conducted to evaluate the impact power of the solenoid using the existing original power supply and compare the results to various combinations of capacitance and voltage to be used in the new power supply. The tests indicated that a 34-mF capacitor bank charged to 65 VDC resulted in better impact performance than the original power supplies set to 160 VDC. Lowering the voltage results in a reduced probability of solenoid failure.

As new instrumentation techniques such as high-speed video and laser interferometry have been introduced into our gun testing, event timing has become critical. To improve the initiation timing, input and output trigger signals became desirable and were included in the new design. A debounce circuit was incorporated to clean up the manual push-button signal to fire the gun and reduce jitter.

The entire firing system including the power supplies is now enclosed within a single 3-U rack mount enclosure. A keyswitch is present to control the system power and a toggle switch selects between electric and percussion primers. Two push-button switches are available for firing the gun. One is the main fire switch, which incorporates a debouncing circuit, while the other is a back-up firing switch to be used if the main fire switch fails. It directly connects the charged capacitor to the firing line, bypassing all of the debouncing circuit should it fail to perform. The trigger input can be used to allow an external device to fire the gun. A single trigger output can be used to trigger other devices or monitor timing. Light-emitting diode (LED) indicators on the front panel indicate power on (Power) and fully charged capacitor bank (Ready). The firing line connects to the unit using a military-style circular bayonet connector.

\section{Circuit Design}

The circuit schematic (appendix A) has two sections. The top encompasses the capacitor banks and voltage charged (Ready) indicator while the bottom section includes the input, output, and debounce circuitry.

There are two capacitor banks, each with its own power supply. The electric primer bank consists of capacitors C1 and C2 and is charged by the 200-VDC power supply V1. Resistor R1 limits charging current to $40 \mathrm{~mA}$. Even though charging occurs in a few seconds, this resistor is mounted to a thermal heat sink to allow for the possible fault condition in which a capacitor or firing line may become shorted. The percussion primer bank consists of capacitors $\mathrm{C} 3-\mathrm{C} 7$ and is charged by a 70-VDC power supply V3. Resistors R10-R12 limit the charging current to $233 \mathrm{~mA}$ and are also mounted to thermal heat sinks to handle a possible fault condition. An LM393 dual voltage comparator chip (X1) monitors the charge voltage of each bank through a voltage divider network and compares it to a reference voltage of $4.7 \mathrm{~V}$ from the zener diode D1. The comparator chip will sink current from the LED D2 to indicate when the capacitor bank is 
greater than approximately 95\% charged. Switch 1 (A and B) is a double-pole double-throw switch that adjusts the system for firing either the electric or percussion primer. Pole A of Switch 1 connects the LED D2 to the output of the comparator that corresponds to either the electric or percussion capacitor bank. Pole B of Switch 1 connects the solid-state fire relay to either the electric or percussion capacitor bank.

The trigger circuitry is powered by a 10-VDC power supply V2. The LED D13 indicates that power is on. The unit can be fired by depressing the Fire button or providing a positive pulse to the Trig In BNC connector. Any signal higher than $1.0 \mathrm{~V}$ will trigger the unit. Overvoltage of the input is prevented by a combination of spark gap X10 and transient voltage diode D10. The spark gap clamps input voltage to $75 \mathrm{~V}$. Resistor R22 limits the surge current while diode D10 further clamps the voltage to $15 \mathrm{~V}$. A 555 timer chip (X12) provides debouncing of the switch while sending a monostable 250-ms pulse to the solid-state relay to fire the primer. Transistor Q1 pulls the trig line of the 555 timer low when the fire button is depressed, or a positive pulse is received at the Trig In connector. The timer then puts out a $10-\mathrm{V}$ pulse to solid-state relay (SSR) 1 to connect the capacitor bank to the firing line, thus initiating the primer. Resistor R30 is in parallel with the firing line connector to dump the energy from the capacitor bank should the firing line not be connected while firing. Diode D12 is a flyback diode to eliminate voltage reversals from the solenoid during operation. The Trig Out signal is provided by transistors Q2 and Q3. This output is protected from overvoltage by transient voltage diode D11 and spark gap $\mathrm{X} 11$ with resistor R29 limiting surge current. The output signal is a $6.8-\mathrm{V}$ positive pulse.

A back-up momentary fire switch is also provided on the front panel. This is intended to be used only if the main firing switch fails to initiate the primer. It bypasses all the trigger conditioning and directly connects the capacitor bank to the firing line. In this mode of operation, no Trig Out signal will be present.

The circuit performance was modeled using MicroCap 10.0 software prior to circuit board construction. Prototype circuit boards were fabricated by a printed circuit board manufacturer (appendix B). A full list of all components used can be found in appendix C.

\section{Unit Construction}

The enclosure is dismantled to cut the panel face, rear, top, and bottom panels with a laser or waterjet (appendix D). The face panel is cut to accept all the buttons, switches, indicators, and connectors. The rear panel is cut to accept a power cord receptacle. The top and bottom panels are cut to provide cooling vents and mounting holes for the power supplies and the circuit board.

The circuit board is populated with components and soldered in place by hand. It is then bench tested and adjustments made to the two potentiometers X2 and X3 to ensure the ready indicator lights up when the two capacitor banks are approximately $95 \%$ charged. 
After installing the photoresist printed face and rear plates, all the indicators, switches, and connectors are then mounted to the front and rear panels. The two power supplies and circuit board are mounted to the bottom panel. Final wiring is done by connecting all the front and rear panel components and power supplies to the circuit board with hook-up wire. Then the enclosure is reassembled to complete the unit.

\section{Field Testing}

The unit was bench tested to ensure performance. A digital oscilloscope was used to record signals during firing. Three channels were simultaneously recorded: (1) Input Trigger, (2) Output Trigger, and (3) the voltage on the firing line. Figure 1 shows the signals recorded for the electric primer test. Figure 2 shows the signals recorded during the percussion primer test.

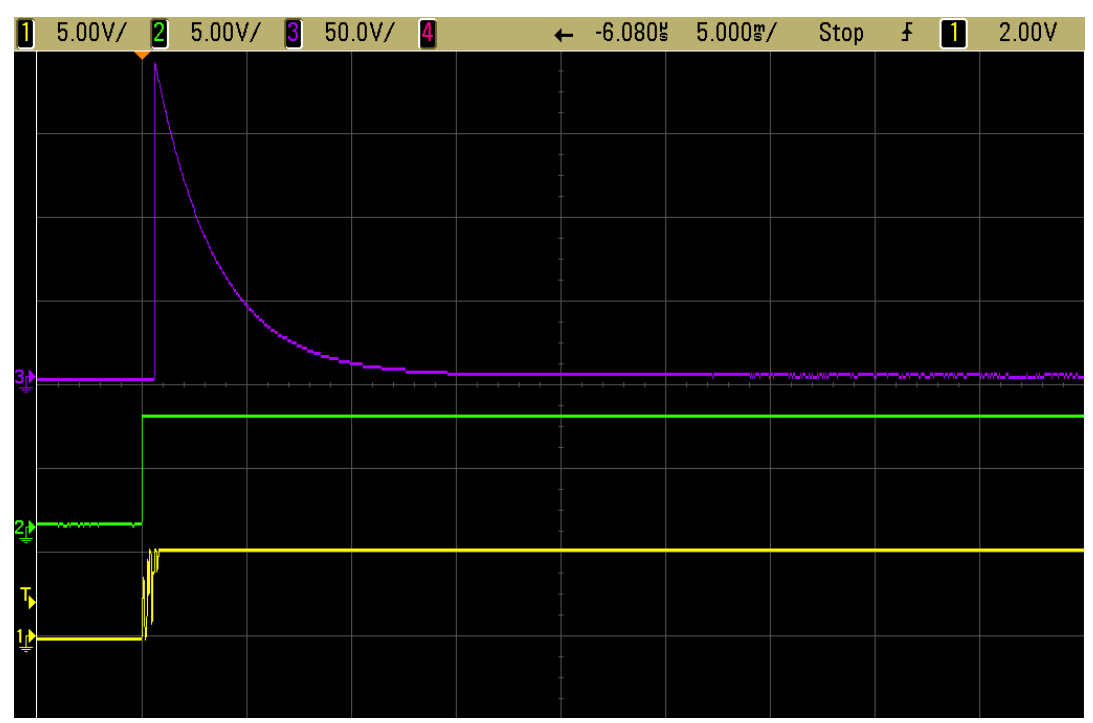

Figure 1. Electric primer signals. 


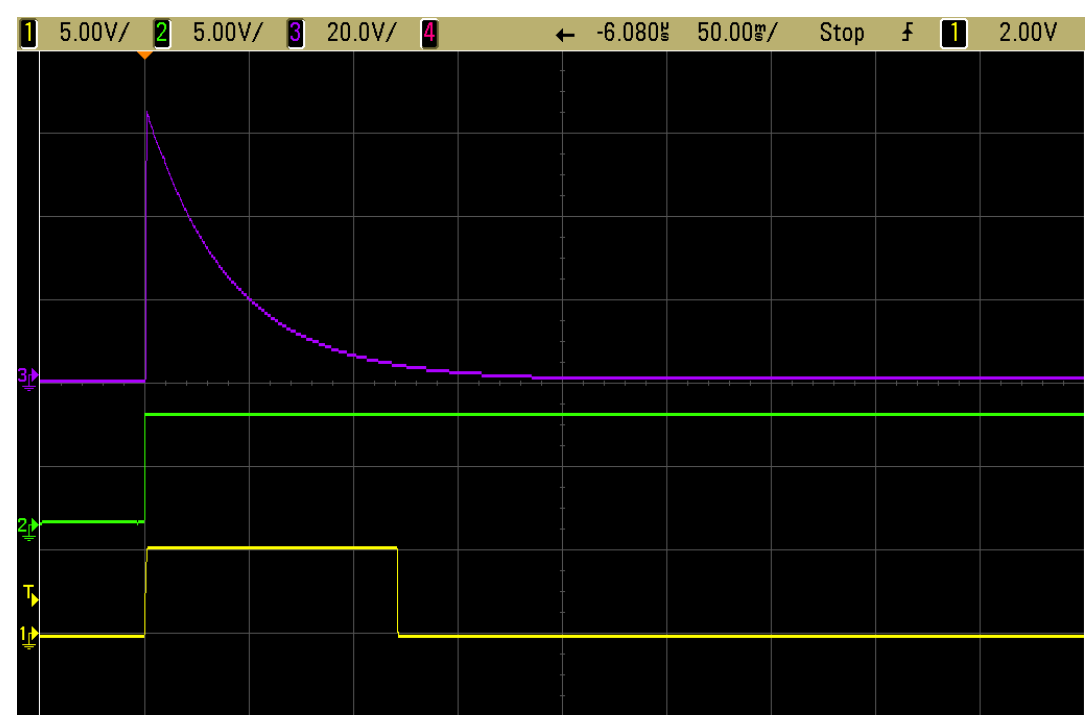

Figure 2. Percussion primer signals.

To measure circuit time delays, the test was repeated with a faster oscilloscope time base. As seen in figure 3 , the time delay between input and output triggers is less than $10 \mu \mathrm{s}$. The delay between trigger input and firing line voltage is $600 \mu$ s due to the turn on time delay of the solid-state relay. Note the noise present on the input trigger line. The fire button was used to trigger the unit, and bouncing of the switch is obvious. The trigger out line and the voltage on the firing line is clean, however, due to the debouncing circuit.

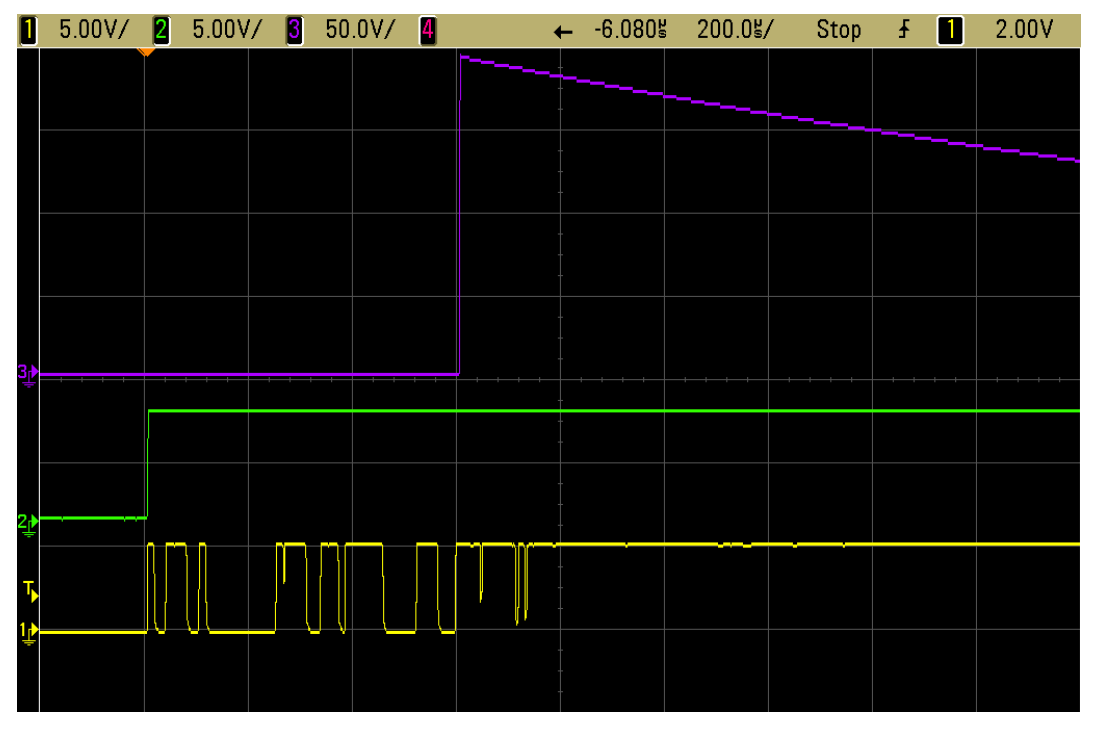

Figure 3. Signals for measuring time delays. 


\section{Conclusions}

The new firing unit is a reliable upgrade to the previous firing system. It was specifically engineered to fire both percussion and electric primers. The debounce circuit produces more accurate timing and firing with modern instrumentation techniques. The addition of trigger input and trigger output gives the unit more flexibility in interfacing with other instruments during testing. Lowering the voltage and increasing the capacitance driving the solenoid will increase the reliability and life of the solenoid. All the delays in the electronics are very repeatable and less than $1 \mathrm{~ms}$ - short compared with the $10 \mathrm{~s}$ of milliseconds required to fire the guns. 


\section{Appendix A. Circuit Schematic}

This appendix appears in its original form, without editorial change. 


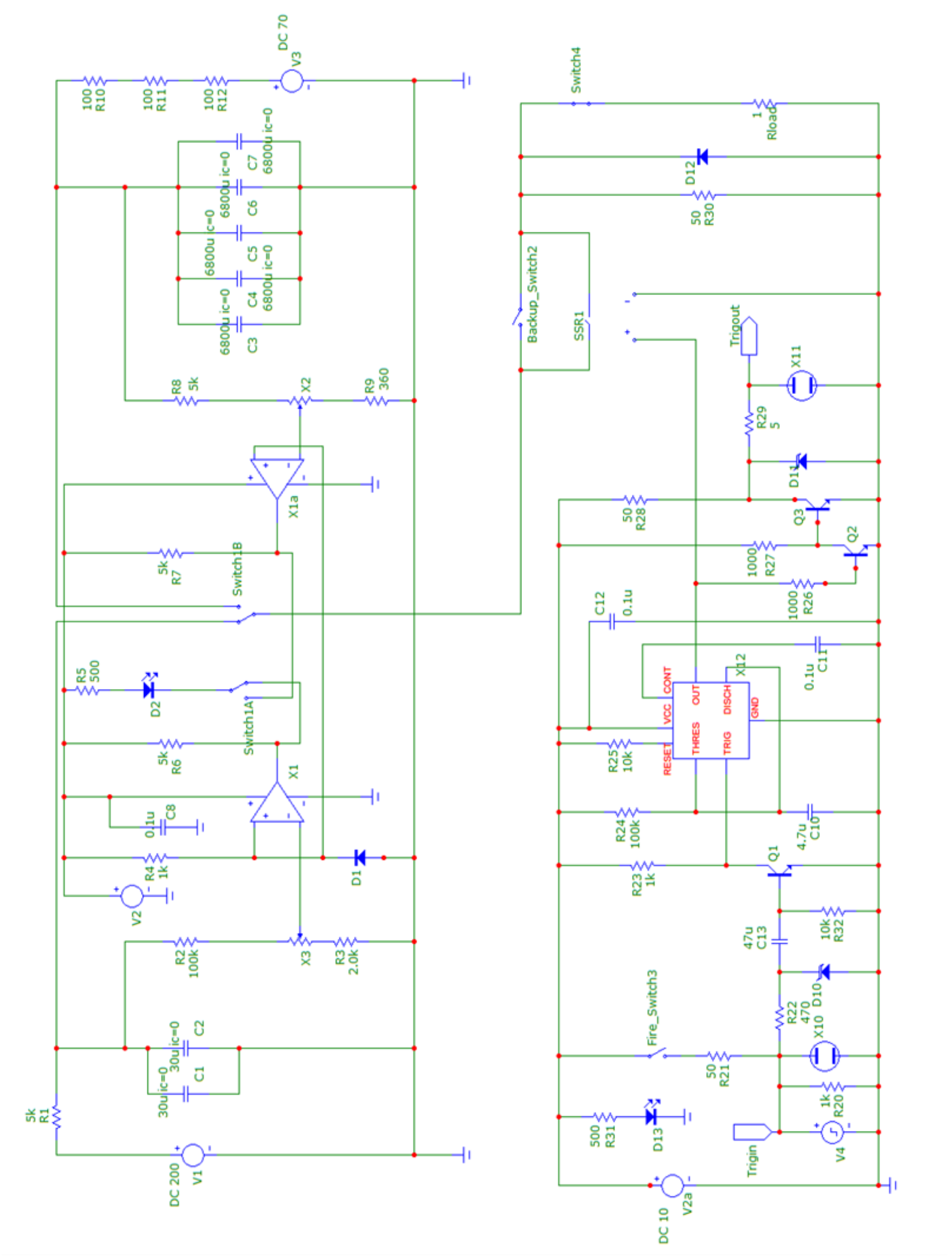


Appendix B. Circuit Board Layout

This appendix appears in its original form, without editorial change. 


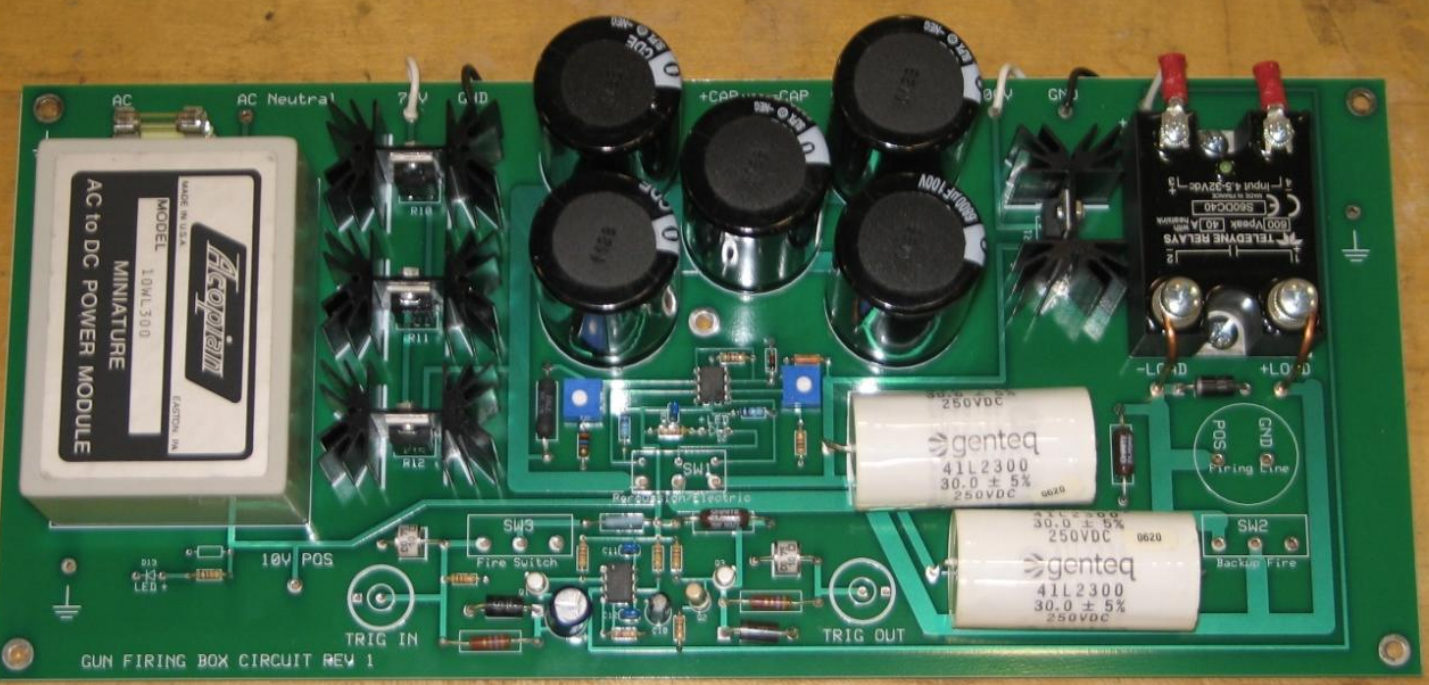




\section{Appendix C. Component List}

This appendix appears in its original form, without editorial change. 


\begin{tabular}{|c|c|c|c|}
\hline & & Nomenclature & Manufacturer Part \# \\
\hline \multicolumn{4}{|c|}{ (All resistors $1 / 4$ watt unless otherwise specified) } \\
\hline $\mathrm{R}$ & 1 & $5 \mathrm{k} 8 \mathrm{~W}$ TO220 & Ohmite TCH35P5K10JE \\
\hline $\mathrm{R}$ & 2 & $100 \mathrm{k} 1 \mathrm{~W}$ & \\
\hline $\mathrm{R}$ & 3 & $2 \mathrm{k}$ & \\
\hline $\mathrm{R}$ & 4 & $1 \mathrm{k}$ & \\
\hline $\mathrm{R}$ & 5 & 500 & \\
\hline $\mathrm{R}$ & 6 & $5 \mathrm{k}$ & \\
\hline $\mathrm{R}$ & 7 & $5 k$ & \\
\hline $\mathrm{R}$ & 8 & $5 \mathrm{k} 3 \mathrm{~W}$ & \\
\hline $\mathrm{R}$ & 9 & 360 & \\
\hline $\mathrm{R}$ & 10 & $1006 \mathrm{~W}$ TO220 & Ohmite TBH25P100RJE \\
\hline $\mathrm{R}$ & 11 & 100 6W TO220 & Ohmite TBH25P100RJE \\
\hline $\mathrm{R}$ & 12 & 100 6W TO220 & Ohmite TBH25P100RJE \\
\hline \multirow[t]{5}{*}{$\mathrm{R}$} & 13 & $1 \mathrm{k}$ & \\
\hline & & Heat Sink & Ohmite \#FA-T220-25E \\
\hline & & Heat Sink & Ohmite \#FA-T220-25E \\
\hline & & Heat Sink & Ohmite \#FA-T220-25E \\
\hline & & Heat Sink & Ohmite \#FA-T220-25E \\
\hline $\mathrm{R}$ & 20 & $1 \mathrm{k}$ & \\
\hline $\mathrm{R}$ & 21 & $501 W$ & \\
\hline $\mathrm{R}$ & 22 & $4700.5 \mathrm{~W}$ & \\
\hline $\mathrm{R}$ & 23 & $1 \mathrm{k}$ & \\
\hline $\mathrm{R}$ & 24 & $100 \mathrm{k}$ & \\
\hline $\mathrm{R}$ & 25 & $10 \mathrm{k}$ & \\
\hline $\mathrm{R}$ & 26 & $1 \mathrm{k}$ & \\
\hline $\mathrm{R}$ & 27 & $1 \mathrm{k}$ & \\
\hline $\mathrm{R}$ & 28 & $503 W$ & \\
\hline $\mathrm{R}$ & 29 & $51 \mathrm{~W}$ & \\
\hline $\mathrm{R}$ & 30 & $502 W$ & \\
\hline $\mathrm{R}$ & 31 & 500 & \\
\hline $\mathrm{R}$ & 32 & $10 \mathrm{k}$ & \\
\hline \multicolumn{2}{|c|}{ Fuse Holder } & $5 \mathrm{~mm}, \mathrm{PCB}$ mount & \\
\hline Fuse & & $1.25 \mathrm{~A}, 5 \mathrm{~mm}$ & \\
\hline C & 1 & 30uf 250VDC film & Genteq 41L2300 \\
\hline C & 2 & 30uf 250VDC film & Genteq 41L2300 \\
\hline C & 3 & 6800 uf $80-100 \mathrm{VDC}$ & SLPX682M100H9P3 \\
\hline C & 4 & 6800 uf $80-100 \mathrm{VDC}$ & SLPX682M100H9P3 \\
\hline $\mathrm{C}$ & 5 & 6800 uf $80-100 \mathrm{VDC}$ & SLPX682M100H9P3 \\
\hline C & 6 & 6800 uf $80-100 \mathrm{VDC}$ & SLPX682M100H9P3 \\
\hline $\mathrm{C}$ & 7 & 6800 uf $80-100 \mathrm{VDC}$ & SLPX682M100H9P3 \\
\hline C & 8 & $100 \mathrm{nf} 50 \mathrm{~V}$ & \\
\hline $\mathrm{C}$ & 10 & 4.7uf $50 \mathrm{~V}$ & \\
\hline C & 11 & $100 \mathrm{nf} 50 \mathrm{~V}$ & \\
\hline
\end{tabular}




\begin{tabular}{|c|c|c|c|}
\hline \multicolumn{2}{|c|}{ C 12} & $100 \mathrm{nf} 50 \mathrm{~V}$ & \multirow[b]{2}{*}{$\begin{array}{l}\text { Or Jumper (cap will cause } \\
\text { solenoid to unlatch automatically }\end{array}$} \\
\hline C & 13 & 47 uf $50 \mathrm{~V}$ & \\
\hline D & 1 & 1N5230B (4.7V zener) & \\
\hline $\mathrm{D}$ & 2 & LED Yellow & Lumex SSI-LXR3816SYD-1 \\
\hline D & 10 & 1.5KE15A & \\
\hline D & 11 & $1.5 \mathrm{KE} 6.8 \mathrm{~A}$ & \\
\hline $\mathrm{D}$ & 12 & IN5408 & \\
\hline $\mathrm{D}$ & 13 & LED Green & Lumex SSI-LXR3816SGD-1 \\
\hline Q & 1 & 2N2222A & \\
\hline Q & 2 & 2N2222A & \\
\hline Q & 3 & $2 \mathrm{~N} 2222 \mathrm{~A}$ & \\
\hline$x$ & 1 & LM393N & \\
\hline$x$ & 2 & pot 100 (1 turn) & Bourns \#3386P-1-101LF \\
\hline $\mathrm{X}$ & 3 & pot $1 \mathrm{k}$ (1 turn) & Bourns \#3386P-1-102LF \\
\hline $\mathrm{x}$ & 10 & Surge Arrestor & CG75L \\
\hline$x$ & 11 & Surge Arrestor & CG75L \\
\hline$x$ & 12 & LM555CN & \\
\hline SW & 0 & Toggle SPST & ALCOSWITCH SWK121F314 \\
\hline SW & 1 & Toggle DPDT & Honeywell 2NT1-3 \\
\hline SW & 2 & Pushbutton mom & Eaton \#8943K28 \\
\hline SW & 3 & Pushbutton mom & Eaton \#8943K28 \\
\hline $\mathrm{V}$ & 1 & Power Supply & Acopian B200GT10 \\
\hline V & 2 & Power Supply & Acopian 10WL300 \\
\hline V & 3 & Power Supply & Acopian B70GT30 \\
\hline SSR & 1 & Solid State Relay & Teledyne \#S60DC40 \\
\hline \multicolumn{4}{|c|}{ Case Parts } \\
\hline & & Circuit board & \\
\hline & & Case & OKW \#M5930035-AL \\
\hline & & Push button guard & Grayhill \#10C1015-1 \\
\hline & & BNC Bulkead Recepticle & Amphenol \#112424 \\
\hline & & BNC Bulkead Recepticle & Amphenol \#112424 \\
\hline & & AC inlet recpticle & Shurter \#6100.3200 \\
\hline & & Power cord & Volex \# 1760210 B1 \\
\hline & & Firing Line Recepticle & Canon \#CA3102E16S-4SB \\
\hline & & Firing Line Plug & Canon \#CA3106E16S-4PB \\
\hline & & Recepticle Cap & Canon \#ICA121003-4 \\
\hline
\end{tabular}


INTENTIONALLY LEFT BLANK. 


\section{Appendix D. Instrument Panels}

This appendix appears in its original form, without editorial change. 


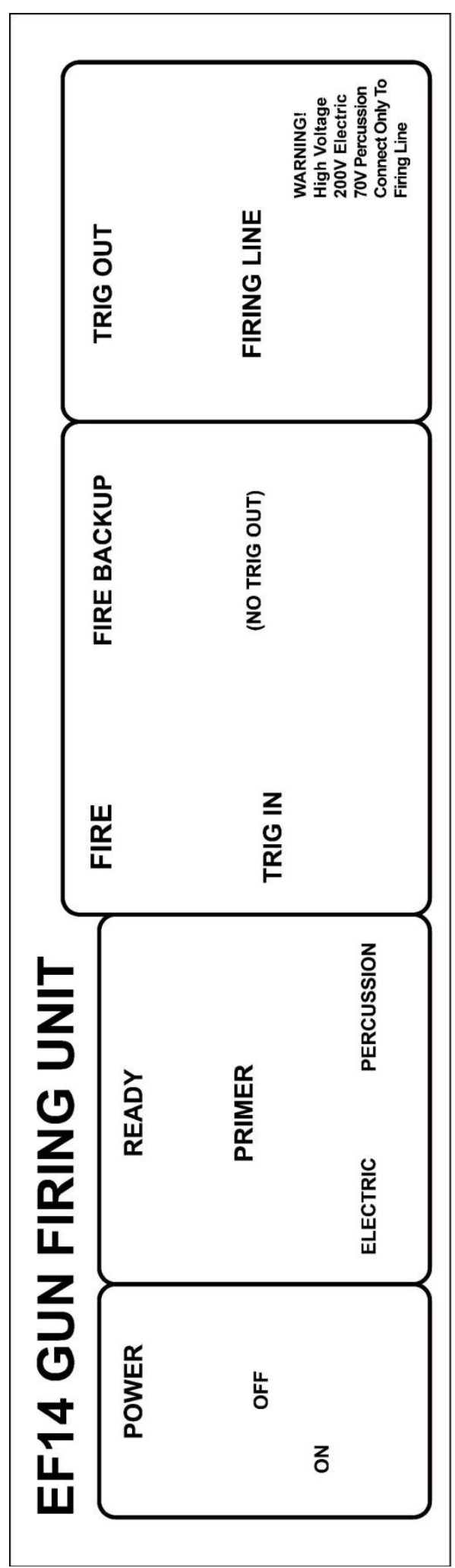

Front Panel Graphics 


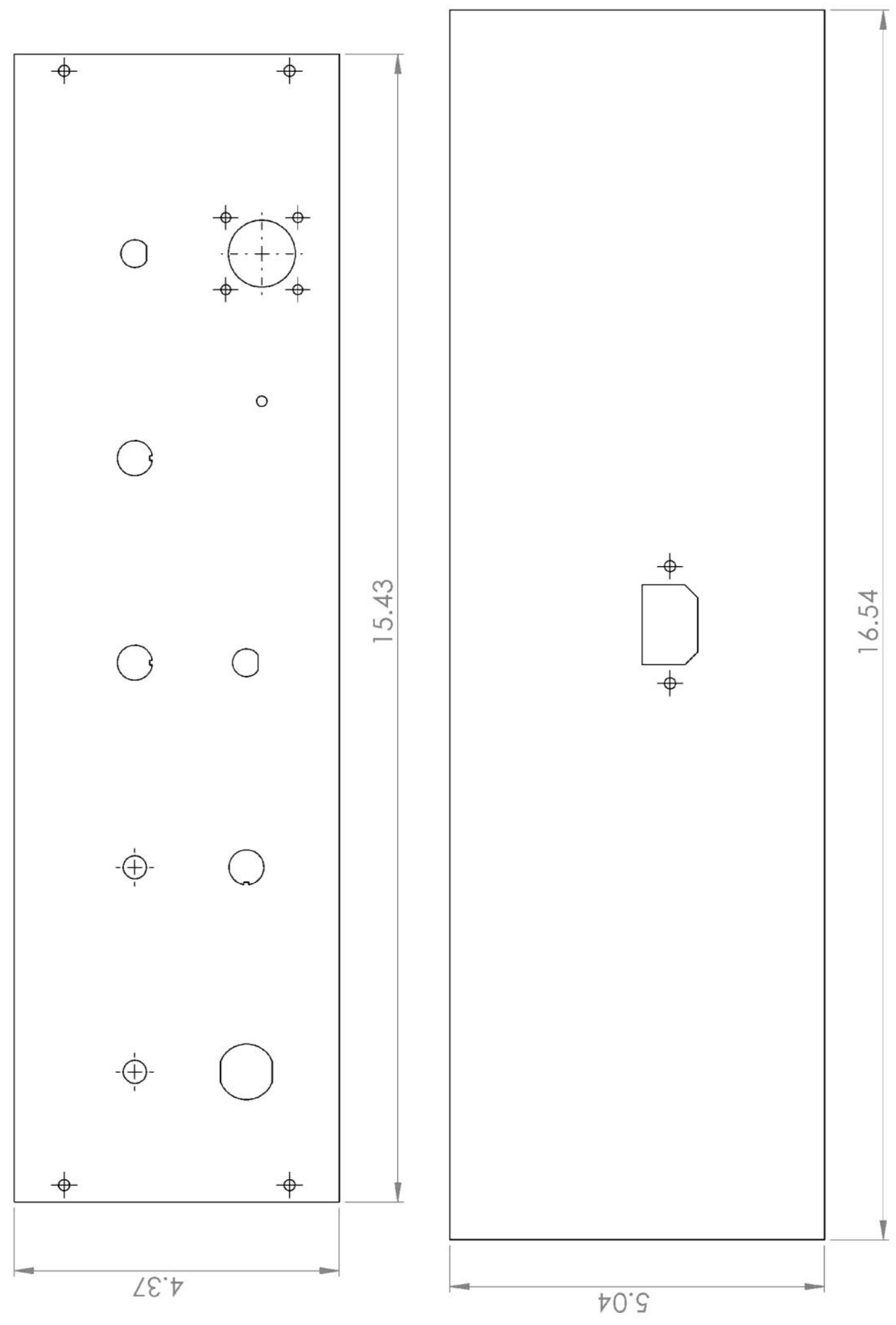

Cutouts for Front and Rear Panels 


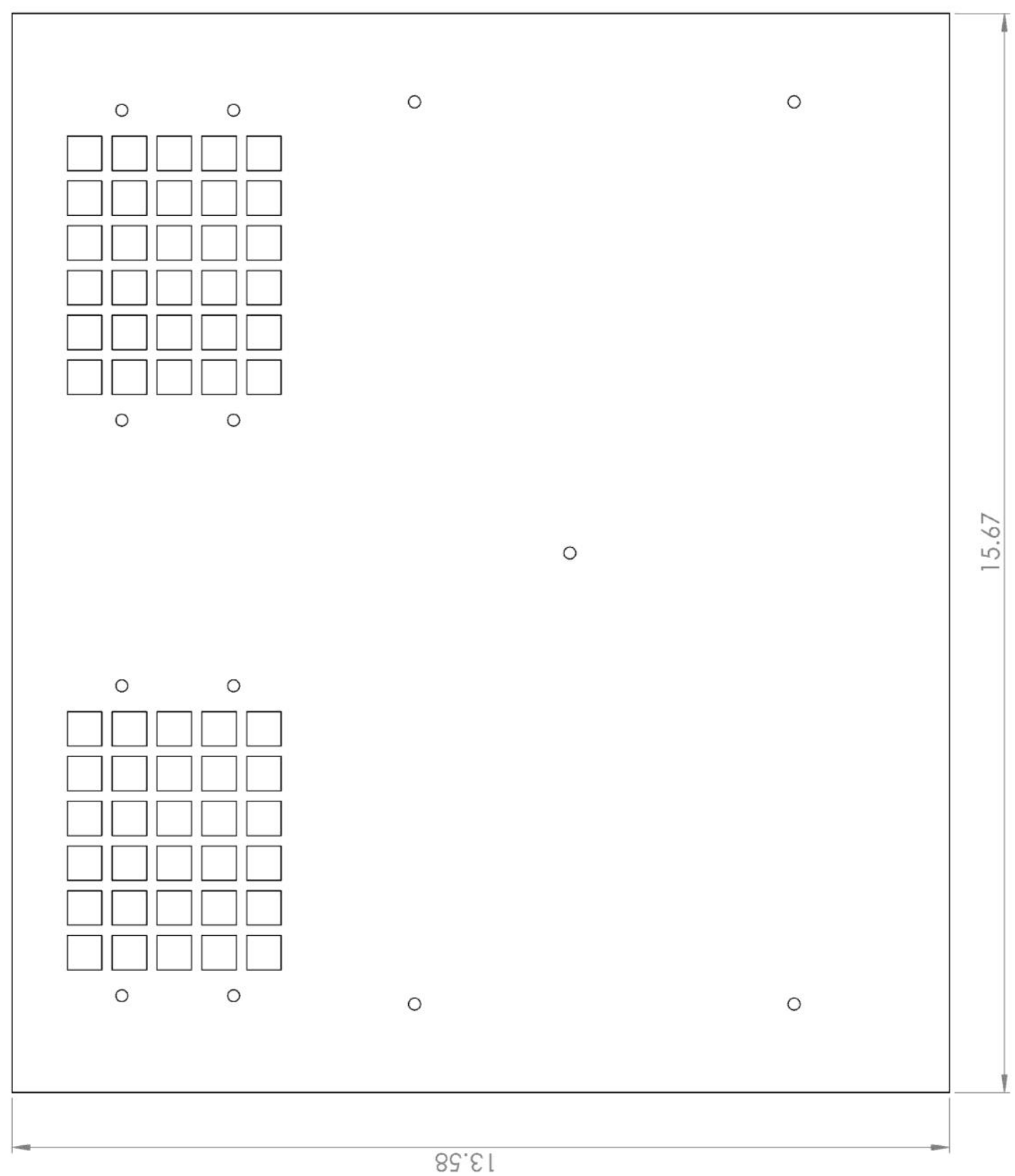

Cutouts for Top and Bottom Panels (identical) 


\section{Appendix E. Instrument Case Interior}

This appendix appears in its original form, without editorial change. 


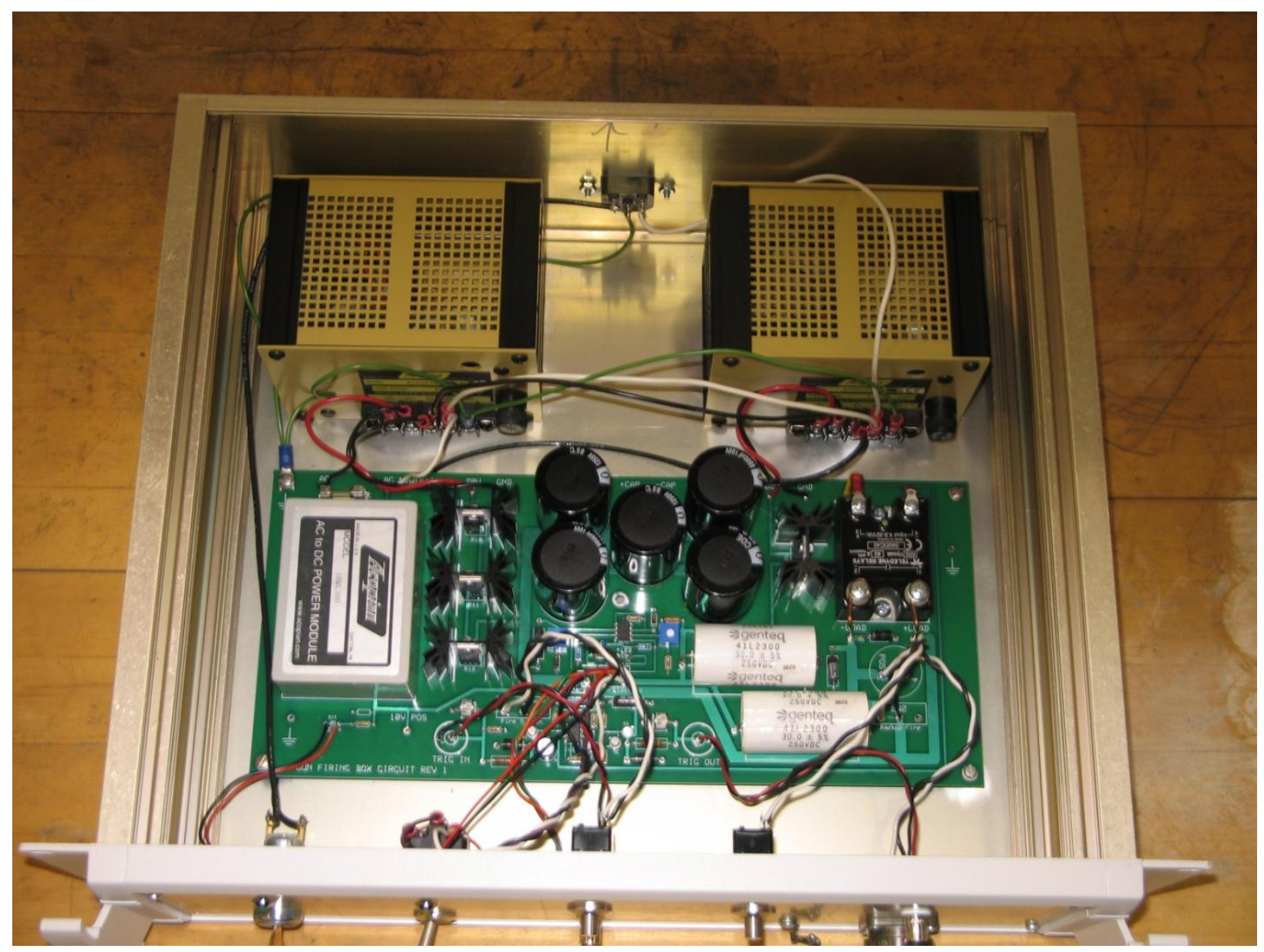




\section{Appendix F. Completed Unit}

This appendix appears in its original form, without editorial change. 


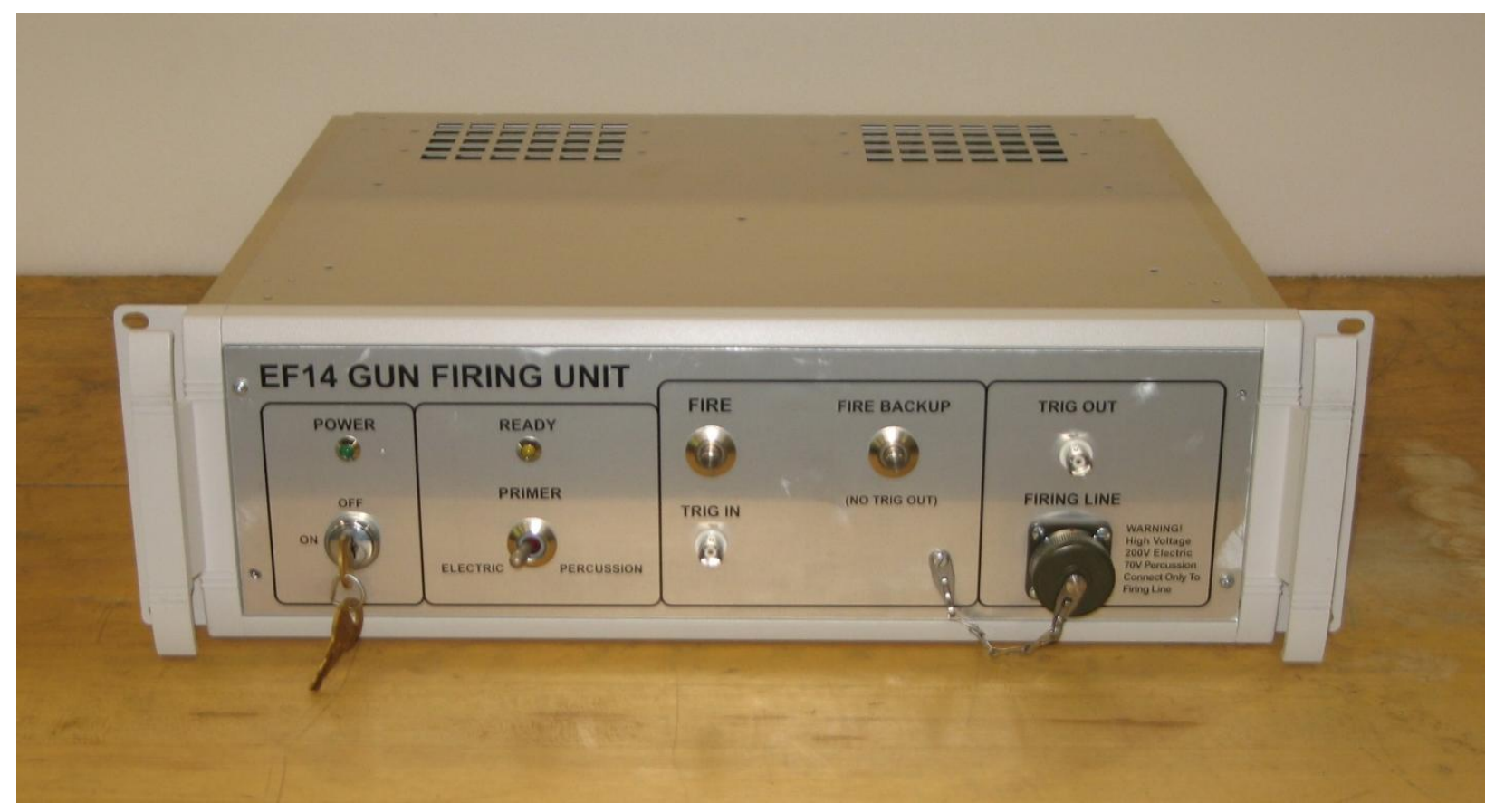




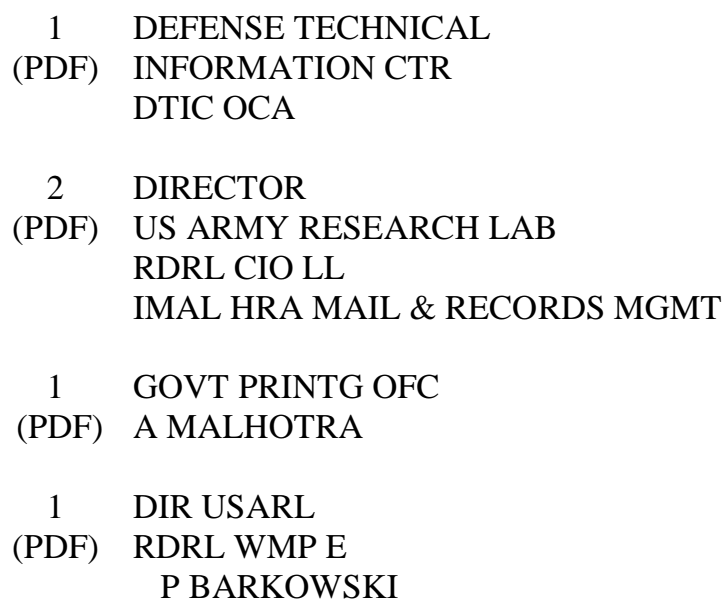


INTENTIONALLY LEFT BLANK. 